\title{
Molecular cloning and characterization of two novel genes on chromosome 8p21.3
}

\begin{abstract}
Through large-scale sequencing of genomic DNA from human chromosome 8p22-p21.3 we have isolated two novel genes, designated $G K 1$ and $G 5$. Their predicted products showed no significant similarity to any known proteins in public databases. A comparison of GK1 cDNA sequences, which encode a 1270-amino-acid protein, with corresponding genomic DNA sequences revealed that this gene consists of 15 exons and spans an approximately 113$\mathrm{kb}$ genomic region. Northern blot analysis revealed ubiquitous expression of 7.0- and 4.4-kb transcripts; in addition, we detected a 5.0-kb skeletal muscle-specific transcript and a $4.0-\mathrm{kb}$ transcript specifically expressed in heart and pancreas. Computer and immunocytochemical analyses of a GK1 Green fluolesent protein (GFP) fused construct indicated that the gene product, which contains putative leucine-zipper domains, was likely to be a mitochondrial protein. The other novel gene, G5, expressed four transcripts $(4.2,2.2,1.7$, and 1.0-kb) ubiquitously; the longer three transcripts, which differed only in the $3^{\prime}$-non coding region, encoded identical 397-amino-acid peptides. The G5 gene consists of 14 exons and spans approximately $52 \mathrm{~kb}$ of genomic DNA; its deduced 397-amino acid product appears to contain coiled-coil domains and a proline-rich region, and to be located in cytoplasm.
\end{abstract}

Key words Large-scale DNA sequencing · In silico cDNA cloning $\cdot 8$ p22-p21.3 $\cdot$ Leucine-zipper domain $\cdot$ Coiled-coil domain

T. Kinjo $\cdot$ M. Isomura $\cdot$ Y. Nakamura $(\bowtie)$

Laboratory of Molecular Medicine, Human Genome Center, Institute of Medical Science, University of Tokyo, 4-6-1

Shirokanedai, Minato-ku, Tokyo 108-8639, Japan

Tel. +81-3-5449-5372; Fax +81-3-5449-5433

e-mail: yusuke@ims.u-tokyo.ac.jp

T. Kinjo $\cdot$ T. Iwamasa

Second Department of Pathology, Faculty of Medicine, The

University of the Ryukyus, Okinawa, Japan

\section{Introduction}

Recent progress in the development of large-scale DNAsequencing technologies and bioinformatics has been contributing to rapid and efficient identification of novel genes. High-throughput automated fluorescent sequencers, as well as high-capacity computation using sophisticated algorithms, have already yielded a huge quantity of DNA sequences from human and other genomes.

Identification of genes from within genomic DNA sequences has become easier since the advent of two computer-assisted in silico cDNA cloning methods. One of them involves searching for homologies between new genomic DNA sequences and the expressed sequence tag (EST) database; more than 800000 ESTs, representing 40000-50000, genes have been archived so far (Rowen et al. 1997), and the number is still growing. The second method applies programs such as GRAIL (Uberbacher and Mural 1991), FEXH (Solovyev et al. 1994), and GENSCAN (Burge and Kerlin 1997) to predict exons from anonymous genomic sequences with reliable sensitivity and accuracy (Claverie et al. 1997; Elkahloun et al. 1997; Ishikawa et al. 1998; Daigo et al. 1999). Thus, sequencing large genomic regions and "trapping" genes within those sequences with the assistance of computer analysis has become a highly efficient and powerful approach for identification of novel genes.

We have been performing large-scale genomic DNA sequencing of the $8 \mathrm{p} 22-\mathrm{p} 21.3$ region, where loss of heterozygosity ( $\mathrm{LOH})$ is frequently observed in carcinomas of liver, lung, colorectum (Emi et al. 1992), and prostate (Bergerheim et al. 1991). Computer analysis of these genomic DNA sequences by GRAIL2 (Xu et al. 1994) and GENSCAN identified 11 genes in this region. We report here the isolation and characterization of 2 of them, both novel: $G K 1$ and G5. The product of $G K 1$ is likely to be located in mitochondria and may be associated with protein-protein interaction. The 65 product may also be associated with protein-protein interaction, but it appears to be located in cytoplasm. 


\section{Materials and methods}

\section{DNA sequencing}

Two BAC clones (15504 and 54f05) and three cosmids (A266, 3040, and A260) corresponding to genomic DNA on human chromosome 8p21.3 were sequenced by a combination of shotgun and primer-walking methods (Daigo et al. 1999). DNA sequences were assembled by means of ABI "Auto Assembler" computer software (Norwalk, CT, USA). Direct-cosmid sequencing, using primers designed from the end-sequences of assembled segments, filled gaps between segments.

\section{Isolation of cDNA}

We used GRAIL2 and GENSCAN to analyze genomic DNA sequences from the target region, and the Repeat Masker program (Washington University, Seattle, Washington, USA) to screen DNA sequences for interspersed repeats such as Alu and L1. The BLAST algorithm (Altschul et al. 1997) was used to compare similarities and identities with known genes and EST sequences in the GenBank and EMBL databases. To investigate whether predicted candidate exons were actually transcribed, exon-connection experiments by reverse-transcriptase polymerase chain reaction (RT-PCR) were performed as described previously (Horii et al. 1993). Connected cDNA fragments were used as probes to screen cDNA libraries constructed from human umbilical-vein endothelial cells (HUVEC) and K562 (a cell line that originated from chronic myeloblastic leukemia).

\section{Northern blot analysis}

Human multiple-tissue blots (Clontech, Palo Alto, CA, USA) were hybridized with cDNA fragments labeled by random-oligonucleotide priming. Prehybridization, hybridization, and washing were performed according to the supplier's recommendations. The blots were auto-radiographed with intensifying screens for $72 \mathrm{~h}$ at $-80^{\circ} \mathrm{C}$.

\section{Green fluoresent protein (GFP)-fused protein assay}

To investigate the intracellular locations of $G K 1$ and $G 5$ proteins, we constructed plasmids to express GFP- $G K 1$ or GFP-G5 constructs. The coding sequences of each gene, including the translation-initiation site, were amplified by Pyrobest DNA polymerase (TaKaRa, Otsu, Shiga, Japan) using human uterus cDNA as template, and inserted into plasmid pEGFP-N1 (Clontech, Palo Alto, CA, USA). The constructed vectors were verified by sequencing on an ABI PRISM 377 instrument and purified by equilibrium centrifugation in $\mathrm{CsCl}$-ethidium bromide gradients.

HepG2 (a cell line that originated from hepatocellular carcinam) cells were maintained in Dulbecco's modified Eagle's medium supplemented with $10 \%$ fetal calf serum, in 35-mm dishes. At 40\%-50\% confluence, the cultures were transfected by lipofection with $2 \mu \mathrm{g}$ of one or the other constructed plasmid. After a 4-h incubation, the cells were washed with fresh medium and incubated for an additional 24 or $48 \mathrm{~h}$. After one or the other of these incubation times, cells were stained with 4', 6-diamidino-2-phenylindole (DAPI) and examined by fluorescence microscopy.

\section{Immunocytochemical analysis}

After transfected HepG2 cells were fixed for $1 \mathrm{~h}$ in $4 \%$ paraformaldehyde/phosphate-buffered saline (PBS), their membranes were rendered permeable by incubation in $0.2 \%$ Triton-X100 in PBS. The cells were incubated overnight in blocking serum (2.5\% normal goat serum in PBS), then for $1 \mathrm{~h}$ at room temperature in the presence of polyclonal murine antibody to human mitochondria, for $1 \mathrm{~h}$ in PBS containing rhodamine-conjugated goat anti-mouse secondary antibody, and for $30 \mathrm{~min}$ for DAPI staining. Images were acquired by fluorescence microscopy.

\section{Results}

\section{Isolation of $G K 1 \mathrm{cDNA}$ clone}

Computer analysis of genomic DNA sequences corresponding to two BAC clones, 15504 and 54f05, and a cosmid clone, A266, predicted 63 possible exons (38 fragments by GRAIL2 with an excellent score and 42 fragments by GENSCAN; 17 were predicted as exons by both programs). Of these exon candidates, 5 (all predicted by GENSCAN) were identical to parts of a single EST sequence (GenBank Accession No. AA459720). To learn whether these exonlike fragments were in fact transcribed in human tissues, we synthesized oligonucleotides corresponding to the candidate regions and performed exon-connection experiments (Fearon et al. 1990). RT-PCR experiments and subsequent DNA sequencing confirmed that all 5 exon-candidate segments were parts of the same transcript. To define the $5^{\prime}$ and $3^{\prime}$ - ends of the transcript we screened two human cDNA libraries, one derived from umbilical-vein endothelial cells and the other from K562 cells, and obtained 16 positive clones. The assembled cDNA sequences consisted of 4252 nucleotides, including an open reading frame of 1308 nucleotides. Northern blot analysis had detected transcripts of 7.0 and $4.4 \mathrm{~kb}$ in all human tissues examined; we also detected a 5.0-kb skeletal muscle-specific transcript and a 4.0-kb transcript specifically expressed in heart and pancreas (data not shown); this cDNA was considered to correspond to the $4.4-\mathrm{kb}$ transcript. To obtain the cDNA corresponding to the $7.0-\mathrm{kb}$ transcript, we performed additional exon-connection experiments and obtained a cDNA of 6362 nucleotides, including an open reading frame of 3810 nucleotides. Comparison of cDNA and genomic DNA sequences defined 15 exons spanning approximately $113 \mathrm{~kb}$ of genomic DNA (Fig. 1). Table 1 documents the nucleotide sequences around the exon-intron boundaries. 
Fig. 1. Genomic structure of $G K 1$, showing locations of exons in each of the transcripts generated by alternative splicing. Coding regions are indicated as filled boxes
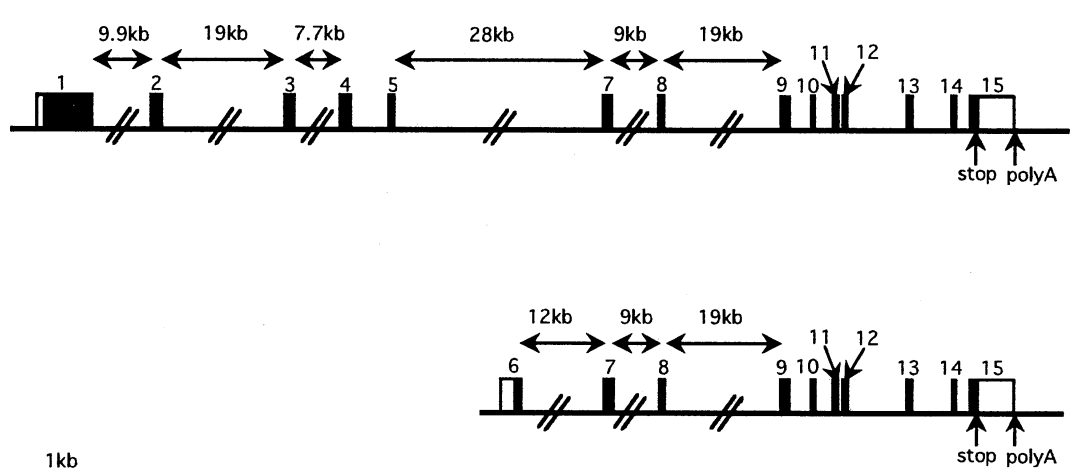

Table 1. Exon - intron boundary sequences of the $G K 1$ gene

\begin{tabular}{|c|c|c|c|c|c|c|}
\hline $\begin{array}{l}\text { Exon } \\
\text { number }\end{array}$ & $\begin{array}{l}\text { Exon length } \\
\text { (bp) }\end{array}$ & $\begin{array}{l}\text { cDNA } \\
\text { position }\end{array}$ & Splice acceptor & Splice donor & $\begin{array}{l}\text { Intron } \\
\text { number }\end{array}$ & $\begin{array}{l}\text { Intron length } \\
\text { (bp) }\end{array}$ \\
\hline 1 & 196 & $1-196$ & attttcacag GGCTCTGCTT & TCCAGTTCTG & 1 & 19,775 \\
\hline 2 & 162 & $197-358$ & aaacccaag GAAAGCCTAC & AGCAACAATT gtaagtcgac & 2 & 7,769 \\
\hline 3 & 135 & $359-493$ & tttattacag CTGGTAATGC & ССТССАAAAG gtacagtcct & 3 & 2,513 \\
\hline 4 & 39 & $494-532$ & tatatcttag GTCCTTCGAG & CTTAATGCAG gtgagtgacc & 4 & 15,549 \\
\hline 5 & 410 & 533-942 & gcatgcacag TGTGATGTGG & TTCCACACAG gtctgtctcg & 5 & 12,704 \\
\hline 6 & 215 & $943-1157$ & cgttttgcag TTGAAAAGAG & GCTGTCTGAG gtaaggaggt & 6 & 9,041 \\
\hline 7 & 67 & $1158-1224$ & ttttccgcag CGGGAGGAAG & GGAGAGCTAG gtaagagctt & 7 & 19,176 \\
\hline 8 & 203 & $1225-1427$ & ctgttttcag TCACTGCTTC & GCAAGAGCAG gtctgtgctt & 8 & 1,198 \\
\hline 9 & 106 & $1428-1533$ & ttgcttacag TTTGACAACT & TCCCTTTCAG gcaaggatgc & 9 & 1,062 \\
\hline 10 & 74 & $1534-1607$ & attttcccag AAATTAAGAA & ATCGCTAGAG gtgggtgaat & 10 & 143 \\
\hline 11 & 96 & $1608-1703$ & tgtgttttag AAGCAAATCA & AGCAAATTTG gtaagttgtg & 11 & 3,224 \\
\hline 12 & 117 & $1704-1820$ & tcctttccag AAAAATCCTC & GGAGAAACTG gtatgtttcc & 12 & 2,767 \\
\hline 13 & 98 & $1821-1918$ & ttatgccaag GTGGACTTCA & CAАТСТCAAG gtaaaaataa & 13 & 842 \\
\hline 14 & 2,334 & $1919-4252$ & tttcttcaag GCAGCTTTCC & GAATACTCAA gaattgcatc & 14 & \\
\hline
\end{tabular}

Characterization of the $G K 1$ gene product

A search for homology of the predicted product of the 4.4kb GK1 transcript (436 amino acids), using the FASTA program (GenomeNet, Human Genome Center, University of Tokyo, Tokyo, Japan) revealed $24 \%$ identity in amino acids (98 identical in 409 amino acids) with Rat synaptonemal complex protein 1 (Meuwissen et al. 1992). The PSORT sequence analysis program (Horton and Nakai 1996) predicted that $G K 1$ is likely to be a mitochondrial protein which has two coiled-coil structures with a leucine-zipper pattern within the coiled-coil conformation (Fig. 2). The Nterminus of $G K 1$ is rich in basic amino acids.

Immunocytochemical analysis, using a GFP-fused $G K 1$ protein, revealed granular bright green signals in the cytoplasm of HepG2 cells (Fig. 3a). The red signals that resulted from staining with antibody to human mitochondria (Fig. $3 \mathrm{~b}$ ) overlapped the green signals of the fusion product (Fig. $3 c$ ), indicating that $G K 1$ was indeed a mitochondrial protein, as the computer analysis had predicted.

\section{Isolation of a $G 5$ cDNA clone}

Computer analysis of genomic DNA sequences present in two cosmid clones (3040 and A260) predicted 25 possible exons ( 8 by GRAIL2, 8 by GENSCAN, and 9 by both). Four of them ( 3 predicted by GENSCAN, 1 by both programs) were identical to one EST sequence (GenBank Ac- cession No. N34601). Using this EST sequence as a probe, we searched the EST database and obtained an overlapping EST (GenBank Accession No. H02721) which contained DNA sequences identical to 3 additional computer-predicted exons ( 1 by GENSCAN, 2 by both programs). RTPCR and subsequent DNA sequencing revealed that all 7 exon-candidate segments were, in fact, parts of the same transcript. We then screened human testis and umbilicalvein endothelial-cell (HUVEC) cDNA libraries, and obtained ten positive clones. The assembled cDNA sequences consisted of 3296 nucleotides, with an open reading frame of 1191 nucleotides. The comparison of cDNA and genomic DNA sequences finally defined 12 exons spanning approximately $52 \mathrm{~kb}$ of genomic DNA (Fig. 4). Table 2 summarizes the nucleotide sequences around the exon-intron boundaries of the $G 5$ gene.

Northern blot analysis revealed that transcripts of four different sizes $(4.2,2.2,1.7$ and $1.0 \mathrm{~kb})$, corresponding to 4 types of cDNA, were expressed in all human tissues examined. However, skeletal muscle, heart, and testis seemed to express the 2.2-kb transcript more abundantly than other tissues (data not shown).

Characterization of the $G 5$ gene product

A search of protein databases, using the FASTA program to detect homologies with the predicted 397-amino-acid protein, revealed that the amino acid sequence of $G 5$ pos- 
sessed $26 \%$ identity to the tyrosine phosphatase $99 \mathrm{~A}$ precursor of Drosophila (Rubin et al. 1991). The homology was limited to a region containing casein kinase 2 phosphorylation sites and N-myristoylation sites of Drosophila tyrosine phosphatase; no significant homology was seen in the cata-

1 MTDDNSDDKIEDELQTFFTSDKDGNTHAYNPKSPPTQNSSASSVNWNSANPDDMVVDYET

61 DPAVVTGENISLSLQGVEVFGHEKSSSDFISKQVLDMHKDSICQCPALVGTEKPKYLQHS

121 CHSLEAVEGQSVEPSLPFVWKPNDNLNRAGYCDALELNQTFDMTVDKVNCTFISHHATGK

18

241

301

361

421

481

54

601

72

84

90

961

1021

1081 KKSLEDLLSEKOESLEKQINDLKSENDALNEKLKSEEOKRRAREKANLKNPQIMYLEOEL

1141 ESLKAVLEIKNEKLHOODIKLMKMEKL VDNNTALVDKLKRFOQENEEL KARMDKHMAISR

1201 QLSTEQAVLOESLEKESKVNKRL SMENEELLWKLHNGDLCSPKRSPTSSAIPLQSPRNSG

1261 SFPSPSISPR

Fig. 2. Deduced amino acid sequence of the GK1 product. Coiled-coil regions are indicated by bold underlining, and leucine-zipper regions by dotted underlining lytic tyrosine-phosphatase domain.

The PSORT sequence analysis program (Horton and Nakai 1996) predicted $G 5$ to be a nuclear protein. However, immunocyochemical analysis of GFP-G5 fused protein detected bright green signals in the cytoplasm of HepG2 cells (Fig. 6), indicating that the gene product is more likely to be a cytoplasmic protein. $G 5$ protein appeared to have two coiled-coil structures in which three or four heptad repeats of hydrophobic residues, including valine, were present in the coiled-coil conformation. In addition, two proline-rich regions (18\% and $21 \%$ in codons $70-163$ and $191-232$, respectively) lie between the coiled-coil domains (Fig. 5).

\section{Discussion}

By combining genomic DNA sequencing with a computerassisted in silico exon-identification method, we have isolated and characterized two novel human genes, termed GK1 and G5, on chromosome 8p21.3. GK1 appears to be a mitochondrial protein, whose N-terminal region is rich in basic amino acids, and contains two putative leucine-zipper motifs and 27 phosphorylation sites. Some known mitochondrial proteins also contain the leucine-zipper motif. For example, human mitochondrial transcription-termination factor, mTERF, binds to DNA as a monomer, although multiple intramolecular leucine-zipper interactions are required to bring the two basic domains into close register with the mTERF-target DNA sequence (Fernandez-Silva et al. 1997). Tim23, a key factor for importation of proteins across the inner mitochondrial membrane, forms dimers through its leucine-zipper motif in a membrane voltagedependent manner (Bauer et al. 1996). The leucine-zipper domain of GK1 may also be important for maintaining this protein's biological function.

The second gene reported here, G5, showed partial similarity to the tyrosine phosphatase 99A precursor of Drosophila (Rubin et al. 1991). Its encoded amino acid sequence contains two coiled-coil motifs and two proline-rich regions.
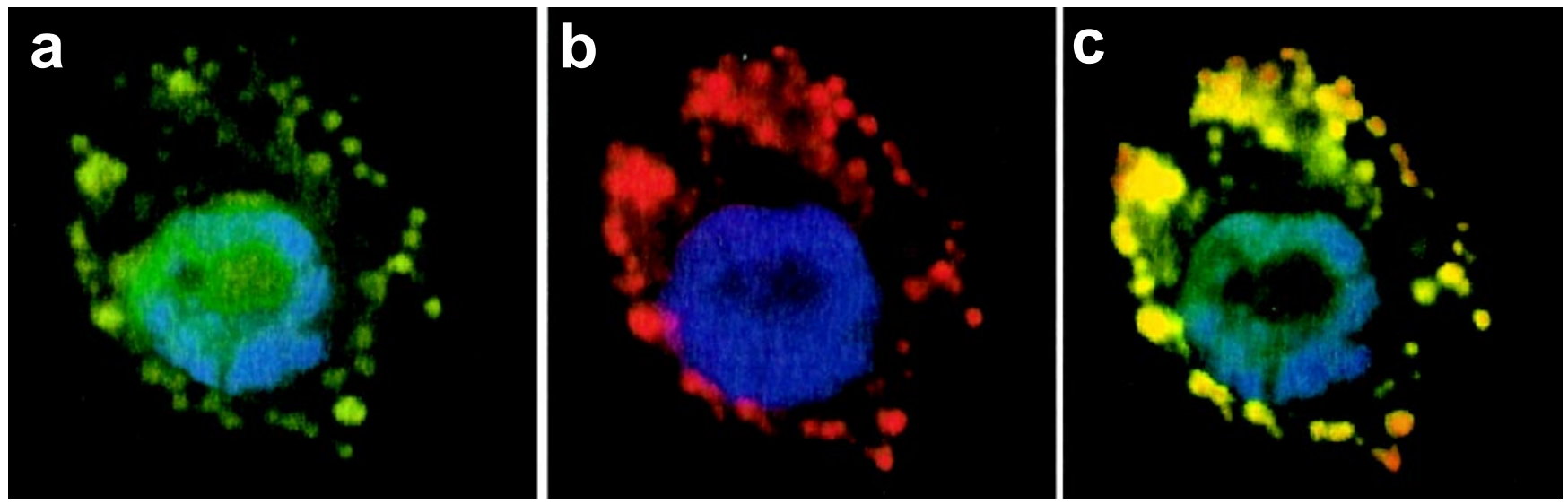

Fig. 3. a Green fluoresent protein (GFP)-fused protein assay. Bright green signals indicate the location of GFP. b,c Immunocytochemistry. Red signals indicate the location of mitochondria, and yellow signals indicate the overlap of GFP-fused GK1 with the mitochondria 
Fig. 4. Genomic structure of the $G 5$ gene. Locations of exons are shown in each of the four transcripts generated by alternative splicing; coding regions are indicated as filled boxes. The $5^{\prime}$ non-coding region of the transcript that includes exon 14 has not yet been found
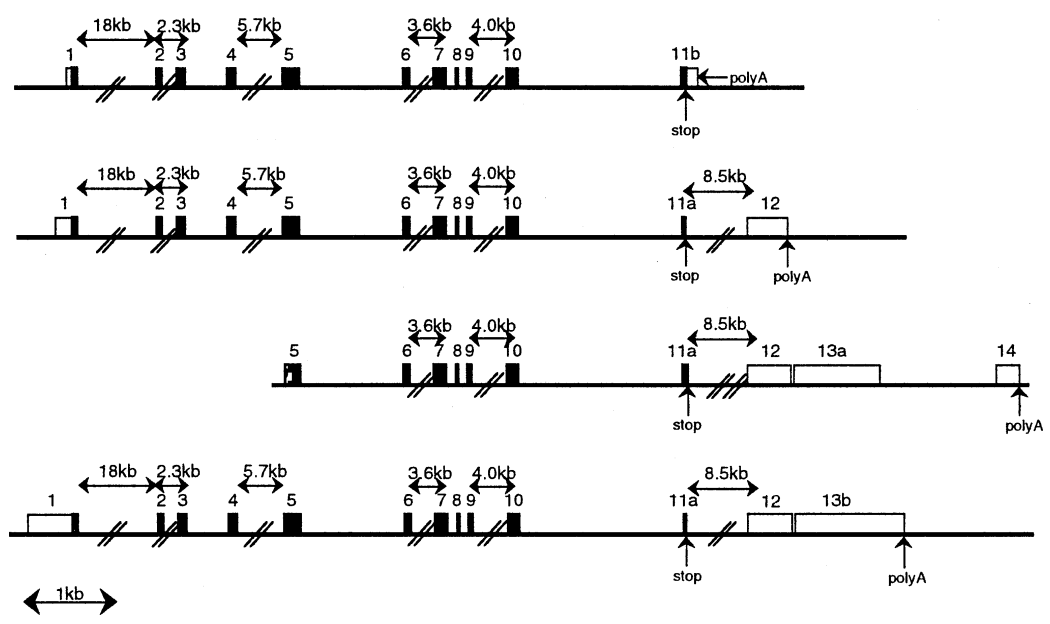

Table 2. Exon - intron boundary sequences of the $G 5$ gene

\begin{tabular}{|c|c|c|c|c|c|c|}
\hline $\begin{array}{l}\text { Exon } \\
\text { number }\end{array}$ & $\begin{array}{l}\text { Exon length } \\
\text { (bp) }\end{array}$ & $\begin{array}{l}\text { cDNA } \\
\text { position }\end{array}$ & Splice acceptor & Splice donor & $\begin{array}{l}\text { Intron } \\
\text { number }\end{array}$ & $\begin{array}{l}\text { Intron length } \\
\text { (bp) }\end{array}$ \\
\hline 1 & 439 & $1-439$ & & CACACTCCAG gtgactggtc & 1 & 18,538 \\
\hline 2 & 75 & $440-514$ & tctcctgcag TATAGCCGAA & ACATTAATAT gtgagtagaa & 2 & 2,280 \\
\hline 3 & 115 & $515-629$ & cctctaccag ATTGCTTCCT & AGTAAACAAT gtatgtatat & 3 & 483 \\
\hline 4 & 101 & $630-730$ & ttactttcag TTTACAATGC & CATTTCСТTA gtaagtatat & 4 & 5,776 \\
\hline 5 & 226 & $731-956$ & ttcttttcag TCTATACAGT & TTCAATACCG gttggtatcg & 5 & 1,438 \\
\hline 6 & 71 & $957-1027$ & ACAAGCCAAA & CAGAACTAAG gtaaacctgg & 6 & 3,560 \\
\hline 7 & 128 & $1028-1155$ & gtgtttctag TGTGTCACAA & GAACTAGCAA gtatgttttc & 7 & 83 \\
\hline 8 & 59 & $1156-1214$ & tatcttacag GAAAAAATCT & TTTAGATAAG gtgagttagt & 8 & 76 \\
\hline 9 & 69 & $1215-1283$ & tctcttttag TATGAATTAC & ACTTAGTGAG gtaagactgt & 9 & 4,029 \\
\hline 10 & 144 & $1284-1427$ & AGCTGTAGTG & AAAGAGAACA gtatgtaata & 10 & 1,730 \\
\hline $11 \mathrm{a}$ & 81 & $1428-1508$ & ATTTGCCACT & TCCACTATAG gtaaattgta & $11 \mathrm{a}$ & 8,559 \\
\hline $11 b$ & 261 & $1428-1688$ & ATTTGCCACT & ATAACTAGTA gaaatctttt & $11 b$ & 8,390 \\
\hline 12 & 572 & $1509-2080$ & ATTTTGCTGG & GAATAAACCA gctgttctta & 12 & 49 \\
\hline $13 \mathrm{a}$ & 1,182 & $2081-3262$ & tgcatttaag AAGCAATACA & CATAATCACA tgagtagttc & $13 \mathrm{a}$ & 1,277 \\
\hline $13 b$ & 805 & $2081-2885$ & tgcatttaag AAGCAATACA & GATAACTGAG gtaagagtgt & $13 b$ & 1,654 \\
\hline 14 & 501 & $3263-3763$ & gtttttatag ACATACACTG & GATATTCAAA atattgatgt & 14 & \\
\hline
\end{tabular}

\begin{abstract}
1 MSWLFPLTKSASSSAAGSPGGLTSLQQQKQRLIESLRNSHSSIAEIQKDVEYRLPFTINN 60
61 LTININILLPPQFPQEKPVISVYPPIRHHLMDKQGVYVTSPLVNNFTMHSDLGKIIQSLL 120

121 DEFWKNPPVLAPTSTAFPYLYSNPSGMSPYASQGFPFLPPYPPQEANRSITSLSVADTVS 180

181 SSTTSHTTAKPAAPSFGVLSNLPLPIPTVDASIPTSQNGFGYKMPDVPDAFPELSELSVS 240

241 QLTDMNEQEEVLLEQFLTLPQLKQIITDKDDLVKSIEELARKNLLLEPSLEAKRQTVLDK 300

301 YELLTQMKSTFEKKMQRQHELSESCSASALQARLKVAAHEAEEESDNIAEDFLEGKMEID 360

361 DFLSSFMEKRTICHCRRAKEEKLQQATAMHSQFHAPL
\end{abstract}

Fig. 5. Deduced amino acid sequence of the G5 product. Coiled coil regions are indicated by heavy underlining, and proline-rich regions by lighter underlines

G5 protein appears to be located in cyto-plasm, suggesting that it may be associated with a variety of cellular functions through its coiled-coil domains in which heptad repeats of hydrophobic residues produce amphipathic $\alpha$-helical segments (Lupas et al. 1991). Although both G5 and GK1 have been partially characterized by computational analysis and expression profiles, their precise physiological and pathophysiological roles remain to be clarified.

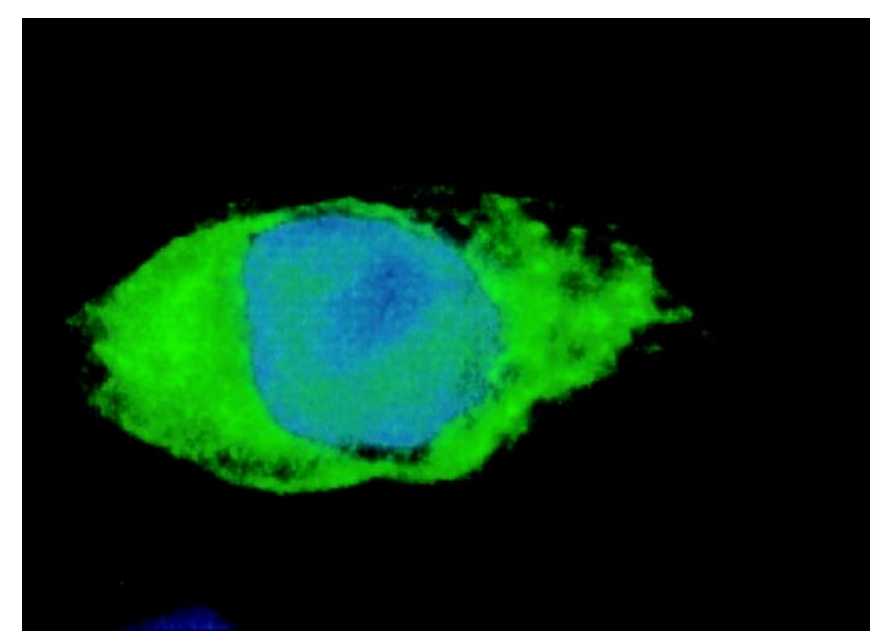

Fig. 6. GFP-fused protein assay for the intracellular location of G5. The photomicrograph was made $24 \mathrm{~h}$ after transfection. 4', 6diamidino-2-phenylindole (DAPI) has stained the nucleus blue; bright green signal indicates the location of the fusion protein 


\section{References}

Altschul SF, Madden TL, Schaffer AA, Zhang J, Zhang Z, Miller W, Lipman DJ (1997) A new generation of protein database search programs. Nucleic Acids Res 25:3389-3402

Bauer FB, Sirrenberg C, Neupert W, Brunner M (1996) Role of Tim23 voltage sensor and presequence receptor in protein import into mitochondria. Cell 87:33-41

Bergerheim USR, Kunimi K, Collins VP, Ekman P (1991) Deletion mapping of chromosome 8,10 , and 16 in human prostate carcinoma. Genes Chromosom Cancer 3:215-220

Burge C, Kerlin S (1997) Prediction of complete gene structures in human genomic DNA. J Mol Biol 268:78-94

Claverie LM, Poirot O, Lopez F (1997) The difficulty of identifying genes in anonymous vertebrate sequences. Comput Chem 21:203-214

Daigo Y, Isomura M, Nishiwaki T, Tamari M, Ishikawa S, Kai M, Murata Y, Takeuchi K, Yamane Y, Hayashi R, Minami M, Fujino MA, Hojo Y, Uchiyama I, Takagi T, Nakamura Y (1999) Characterization of a 1200-kb genomic segment of chromosome 3p22-p21.3. DNA Res 6:1-8

Elkahloun AG, Kritzman DB, Wang Z, Hofmann TA, Roe B, Melzer PS (1997) Transcript mapping in a 46-kb sequenced region at the core of 12q13.3 amplification in human cancers. Genomics 42:295-301

Emi M, Fujiwara Y, Nakajima T, Tsuchiya E, Tsuda H, Hirohashi S, Maeda Y, Tsuruta K, Miyaki M, Nakamura Y (1992) Frequent loss of heterozygosity for loci on chromosome $8 \mathrm{p}$ in hepatocellular carcinoma, colorectal cancer, and lung cancer. Cancer Res 52:5368-5372

Fearon ER, Cho KR, Nigro JM, Kern SE, Simonds JW, Ruppert JM, Hamilton SR, Preisinger AC, Thomas G, Kinzlar KW, Vogelstein B (1990) Identification of a chromosome $18 \mathrm{q}$ gene that is altered in colorectal cancers. Science 247:49-56

Fernandez-Silva P, Martinez-Azorin F, Micol V, Attardi G (1997) The human mitochondrial transcription termination factor (mTERF) is a multizipper protein but binds to DNA as a monomer, with evidence pointing to intramolecullar leucine zipper interactions. EMBO J 16:1066-1079

Horii A, Nakatsuru S, Ichii S, Nagase H, Nakamura Y (1993) Multiple forms of the APC transcripts and their tissue-specific expression. Hum Mol Genet 2:283-287

Horton P, Nakai K (1996) A probabilistic classification system for predicting the cellular localization sites of proteins. Intelligent System Mol Biol 4:109-115

Ishikawa S, Kai M, Murata, Tamari M, Daigo Y, Murano T, Ogawa M, Nakamura Y (1998) Genomic organization and mapping of the human activin receptor type IIB(hActR-IIB)gene. J Hum Genet 43:132-143

Lupas A, van Dyke M, Stock J (1991) Predicting coiled coils from protein sequences. Science 252:1162-1164

Meuwissen RL, Offenberg HH, Dietrich AJ, Riesewijk A, van Iersel M, Heyting C (1992) A coiled-coil related protein specific for synapsed regions of meiotic prophase chromosomes. EMBO J 13:5091-5100

Rowen L, Mahairas G, Hood L (1997) Sequencing the human genome. Science 278:605-607

Rubin GM, Cuang P-T, Hariharan IK (1991) Cloning and characterization of receptor-class phosphotyrosine phosphatase gene expressed on central nervous system axons in Drosophila melanogaster. Proc Natl Acad Sci USA 88:11266-11270

Solovyev VV, Salamov AA, Lawrence CB (1994) Predicting internal exons by oligonucleotide composition and discriminate analysis of spliceable open reading frames. Nucleic Acids Res 22:5156-5163

Uberbacher EC, Mural RJ (1991) Locating protein-coding regions in human DNA sequences by a multiple sensor-neural network approach. Proc Natl Acad Sci USA 88:11261-11265

Xu Y, Mural RJ, Uberbacher EC (1994) Constructing gene models from accurately predicted exons; an application of dynamic programming. Comput Appl Biosci 10:613-623 